\title{
Longitudinal survival trends of patients with cancer with surgically managed appendicular metastatic bone disease: systematic review
}

\author{
Annalise Abbott, MD \\ Joseph K. Kendal, MD, MSc \\ Christopher Hewison, MD \\ Shannon Puloski, MD \\ Michael Monument, MD, MSc
}

Accepted Nov. 5, 2020

\author{
Correspondence to: \\ M. Monument \\ McCaig Tower, Foothills Medical Centre \\ University of Calgary \\ 3134 Hospital Dr NW \\ Calgary $A B$ T2N 5A1 \\ mjmonume@ucalgary.ca
}

Cite as: Can J Surg 2021 November 2; 64(6). doi: $10.1503 / \mathrm{cjs} .015520$

\begin{abstract}
Background: Advances in systemic cancer therapies have improved survival for patients with metastatic carcinoma; however, it is unknown whether these advances have translated to improved survival for patients with appendicular metastatic bone disease (A-MBD) after orthopedic interventions. We conducted a study to evaluate the trend in overall survival for patients who underwent orthopedic surgery for A-MBD between 1968 and 2018.

Methods: A systematic search of Embase and Medline to identify studies published since 1968 evaluating patients treated with orthopedic surgery for A-MBD was conducted for a previously published scoping review. We used a meta-regression model to assess the longitudinal trends in 1-, 2- and 5-year overall survival between 1968 and 2018. The midpoint year of patient inclusion for each study was used for analysis. We categorized primary tumour types into a tumour severity score according to prognosis for a further meta-regression analysis.
\end{abstract}

Results: Of the 5747 studies identified, 103 were retained for analysis. Meta-regression analysis showed no significant effect of midpoint study year on survival across all time points. There was no effect of the weighted average of tumour severity scores for each study on 1-year survival over time.

Conclusion: There was no significant improvement in overall survival between 1968 and 2018 for patients with A-MBD who underwent orthopedic surgery. Orthopedic intervention remains a poor prognostic variable for patients with MBD. This finding highlights the need for improved collection of prospective data in this population to identify patients with favourable survival outcomes who may benefit from personalized oncologic surgical interventions.

Contexte : Les progrès dans les traitements systémiques du cancer ont mené à une amélioration de la survie des patients atteints d'un carcinome métastatique; cependant, on ne sait pas si ces avancées ont amélioré la survie des patients atteints de métastases osseuses appendiculaires après une intervention en chirurgie orthopédique. Notre étude visait à évaluer l'évolution de la survie générale des patients ayant subi une chirurgie orthopédique pour ce type de métastases entre 1968 et 2018.

Méthodes : Nous avions déjà effectué pour une revue exploratoire (publiée) une recherche systématique dans Embase et Medline pour recenser les études publiées depuis 1968 qui évaluaient des patients ayant subi une intervention chirurgicale en orthopédie pour une métastase osseuse appendiculaire. Nous avons utilisé un modèle de méta-régression pour évaluer les tendances longitudinales dans la survie à 1 , à 2 et à 5 ans entre 1968 et 2018 . Aux fins de l'analyse, nous avons utilisé le point médian de l'année où les patients ont été inclus dans chaque étude. Pour une analyse par méta-régression subséquente, nous avons attribué à chaque type de tumeur primaire un score de gravité en fonction du pronostic.

Résultats : Parmi les 5747 études recensées, 103 ont été retenues pour une analyse. L'analyse par méta-régression n'a montré aucun effet significatif de l'année de l'étude (point médian) sur la survie à tous les jalons. Le score de gravité moyen pondéré de chaque étude n'a eu aucune incidence sur l'évolution de la survie à 1 an dans le temps.

Conclusion : Aucune amélioration significative de la survie générale n'a été observée de 1968 à 2018 pour les patients atteints d'une métastase osseuse appendiculaire qui ont subi une intervention en chirurgie orthopédique. L'intervention orthopédique demeure une variable associée à un pronostic sombre pour les patients atteints de métastases osseuses. Ces résultats viennent souligner le besoin d'améliorer la collecte de données prospectives dans cette population, afin de mieux repérer les patients ayant de bonnes chances de survie qui pourraient bénéficier d'une intervention chirurgicale oncologique personnalisée. 
$\mathbf{T}$ he burden of bone metastasis is considerable, with an estimated 280000 new cases per year in the United States. ${ }^{1}$ The extremities, particularly the femur, humerus and tibia, are common sites of bone metastasis. ${ }^{2}$ The morbidity associated with appendicular metastatic bone disease (A-MBD) poses a challenge for orthopedic surgeons, as bony involvement is a sign of advanced disease and affects quality of life substantially. ${ }^{3}$ The role of orthopedic surgery in this palliative setting is not to improve survival but, rather, to alleviate pain and restore musculoskeletal function for the remaining lifespan of the patient while balancing the morbidity associated with surgery. ${ }^{3,4}$

Overall survival in patients with cancer is increasing annually. ${ }^{5}$ Improvements in survival have also been observed in those with metastatic cancer, including difficult-to-treat metastatic cancers such as renal cell carcinoma, lung cancer and melanoma. ${ }^{5-9}$ Using Surveillance, Epidemiology, and End Results (SEER) Program data, Jemal and colleagues ${ }^{6}$ found significant improvements from 1975 to 2012 in 5-year survival for metastatic cancers to all distant sites, especially for lung cancer (relative increase $122 \%$ ), breast cancer (relative increase $80 \%$ ) and renal cell cancer (relative increase $72 \%$ ), all of which commonly metastasize to bone. The improvement in survival among patients with metastatic cancer has been attributed to modern targeted systemic therapies, earlier detection of metastatic disease, more aggressive disease management, and improved screening and diagnostic imaging. ${ }^{7-15}$

Current orthopedic management of A-MBD is based on the premise that survival for these patients remains limited. ${ }^{2,10,16,17}$ Deciding whether to operate and which reconstruction technique to use requires knowledge of the patient's prognosis and is heavily influenced by a variety of factors, such as primary tumour type, extent of metastatic disease, functional status and, more recently, molecular cancer genotypes predictive of sensitivities to targeted therapies. Although standard protocols are lacking, patients with extensive disease and a predicted short life expectancy are often treated with less-invasive strategies, whereas those with estimated longer life expectancies are considered for invasive procedures and more durable reconstructive strategies. ${ }^{4,18-20}$ Furthermore, in patients with oligometastatic disease or favourable molecular profiles, more aggressive orthopedic procedures may have local control or survival benefits. ${ }^{21-23}$ However, outcomes after orthopedic surgery in this population are difficult to determine given the lack of prospective research in this field and the heterogeneity in primary tumour types, location of metastases, extent of metastatic disease and the patient's overall health. ${ }^{2}$ One-year survival rates are very heterogeneous, ranging from $17 \%$ to $69.5 \%$ for all primary tumour types since $1990 .{ }^{24}$

It remains unclear whether the improved outcomes seen in patients with metastatic cancer have been attained in those with A-MBD after orthopedic management. To our knowledge, there are no longitudinal studies analyzing trends in mortality rates in this population. The purpose of this study was to evaluate the trends from 1968 to 2018 in overall survival in patients who underwent orthopedic surgery for A-MBD to determine whether survival in this patient population improved over time. We chose this time frame as a 50 -year period in which major advances were made in cancer care.

\section{Methods}

The study has been registered with the International prospective register of systematic reviews (PROSPERO) (registration CRD42018102980). The systematic review protocol was conducted with the use of the Preferred Reporting Items for Systematic Reviews and MetaAnalyses (PRISMA) guidelines.

\section{Search strategy}

A comprehensive literature search of Medline and Embase databases to identify studies published since 1968 evaluating patients treated with orthopedic surgery for A-MBD was conducted for a previously published scoping review. ${ }^{25}$ The search strategy is presented in Appendix 1 (available at canjsurg.ca). The search was updated in September 2018 by 3 independent reviewers (A.A., J.K.K. and M.M.), and studies identified from the scoping review were screened for inclusion. A fourth independent reviewer (C.H.) repeated the search in full. Any discrepancy between reviewers was discussed and reconciled. The search limits were English language, studies conducted in humans and full text available. The abstracts were screened independently for inclusion, then full-text screening was performed for final inclusion. In addition, reference lists of retrieved papers and review articles were screened for inclusion.

\section{Study selection}

Key inclusion criteria were metastatic carcinoma or hematologic malignant disease to bone, surgery to treat A-MBD, age older than 18 years and survival outcomes reported. Studies were excluded if there were fewer than 10 patients, or if they included primary bone tumours or axial bone metastases (spine or pelvis). Only complete data sets with adequate follow-up to report survival data were included; abstracts, reviews, technique papers and unpublished studies were excluded.

For each eligible study, we recorded the following information: year of publication, level of evidence, first year of patient inclusion, last year of patient inclusion, number of patients, age, median survival, mean survival, 1-year survival, 2-year survival, 5-year survival, primary tumour types included, survival by primary tumour type and method of fixation. 


\section{Assessment of methodologic quality and level of evidence}

We assessed the methodologic quality of all included studies using the Methodological Index for Non-Randomized Studies (MINORS) scale, a validated scale for nonrandomized studies. ${ }^{26}$ Studies with a score of 12 or higher were considered to have "high" methodologic quality; those with a score of 9-11, "moderate" methodologic quality; and those with a score of 8 or less, "low" methodologic quality. All included studies were assessed independently by 2 authors (A.A. and C.H.); discrepancies were resolved by consensus. In addition, we assessed level of evidence using Spindler and colleagues ${ }^{27}$ chart.

\section{Statistical analysis}

The primary outcomes of interest were overall survival and the longitudinal trend of overall survival from 1968 to 2018. We defined survival as the time from orthopedic surgery until death. We analyzed the data according to the median date of the capture period during which patients were included in each study. All data were summarized descriptively. Quality-assessment scores were reported as mean and standard deviation (SD). We used a randomeffects meta-regression model to assess differences in overall survival distributions over the study period. We analyzed 1-year, 2-year and 5-year survival independently. We used the arcsine data transformation for meta-regression analysis and to obtain $95 \%$ confidence intervals (CIs). For all analyses, we report the $I^{2}$ statistic to estimate the variation across studies attributable to heterogeneity. We performed subgroup analysis of primary tumour type to determine mean 1-year survival in patients with breast, renal and lung cancer. Inadequate study numbers prevented further analysis of other primary tumours or any longitudinal survival analysis for any primary tumour subtypes.

We also used a meta-regression model to correlate the trend in primary tumour distribution within the data set with overall survival over time. To develop a simple prognostic scale for cancer diagnosis, we categorized each primary tumour type by prognosis based on the 5 -year relative survival rates published in the 2018 SEER database. ${ }^{5}$ Breast, prostate and thyroid cancer and multiple myeloma were assigned a severity score of 1 (5-yr survival rate $>20 \%$ ); renal cell, gastrointestinal and other cancers (apart from lung and hepatocellular cancer) and melanoma were assigned a severity score of 2 (5-yr survival rate $10 \%-20 \%$ ); and lung and hepatocellular cancer were assigned a severity score of 3 ( 5 -yr survival rate $<10 \%)$. We calculated a weighted average of the severity scores for each study and included it in the meta-regression to determine whether it influenced survival over time. There were insufficient data reported to use other markers of disease severity, such as presence of visceral metastasis, pathologic fracture, multiple bone metastases and Eastern Cooperative Oncology Group Scale of Performance Status, in this score.

\section{Results}

The literature search identified 5747 unique titles through the database search and review of cited publications. After primary and secondary screening, 103 studies were retained for analysis (Figure 1).

A total of 6994 patients were included across all studies. The mean age was 62.1 (SD 7.1) years $(n=6418)$. The primary tumour type was reported for 5728 patients, and the method of fixation was reported for 5856 patients. The baseline characteristics by decade are summarized in Table 1.

\section{Methodologic quality and level of evidence}

The mean MINORS score was 7.2 (SD 3.9), indicating low methodologic quality. Eleven studies were deemed level III evidence, and the remainder were deemed level IV evidence.

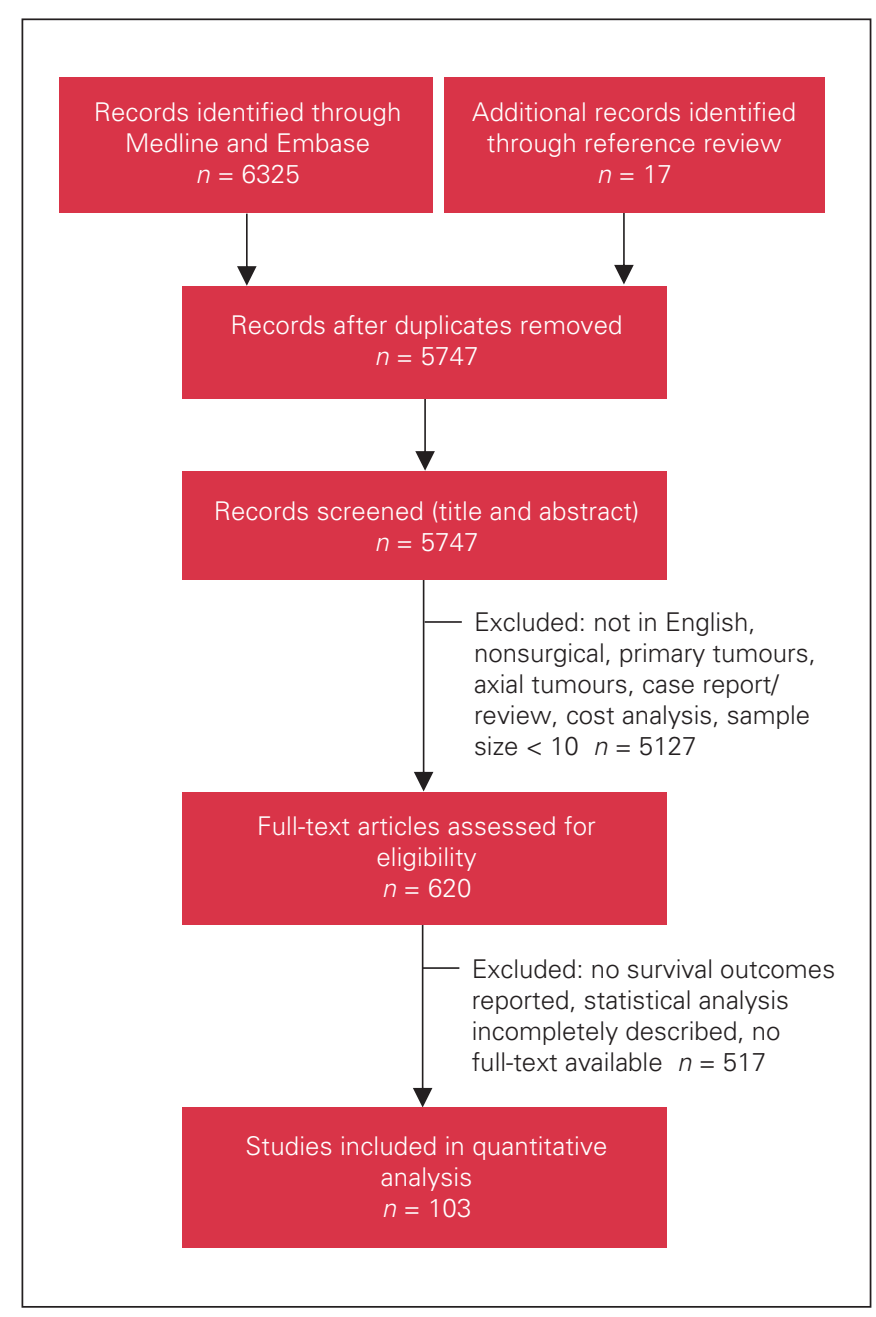

Fig. 1. Flow diagram showing study selection. 
Table 1. Demographic characteristics of patients with cancer with surgically managed appendicular metastatic bone disease by period/decade

\begin{tabular}{|c|c|c|c|c|c|c|}
\hline \multirow[b]{2}{*}{ Characteristic } & \multicolumn{6}{|c|}{ Period/decade; no. (\%) of patients* } \\
\hline & 1968-1969 & 1970-1979 & 1980-1989 & 1990-1999 & 2000-2009 & 2010-2018 \\
\hline No. of studies & 3 & 4 & 8 & 33 & 43 & 13 \\
\hline No. of patients & 191 & 146 & 680 & 2067 & 2900 & 1010 \\
\hline Age, mean $\pm S D, y r$ & $58.8 \pm 1.8$ & $61 \pm 2.9$ & $63.1 \pm 3.7$ & $61.1 \pm 10.8$ & $62.4 \pm 4.3$ & $63.1 \pm 3.7$ \\
\hline \multicolumn{7}{|l|}{ Primary cancer ( $n=5728$ ) } \\
\hline Breast & $127(66.7)$ & $96(66.0)$ & $208(30.6)$ & 775 (37.5) & $829(28.6)$ & $290(28.7)$ \\
\hline Renal & $11(5.6)$ & $6(4.1)$ & $338(49.7)$ & $395(19.1)$ & $412(14.2)$ & $113(11.2)$ \\
\hline Lung & $16(8.6)$ & $14(9.5)$ & $33(4.9)$ & $258(12.5)$ & $455(15.7)$ & $217(21.5)$ \\
\hline Prostate & $2(1.2)$ & $5(3.4)$ & $15(2.2)$ & $194(9.4)$ & $252(8.7)$ & $53(5.2)$ \\
\hline Multiple myeloma & $9(4.9)$ & $10(6.8)$ & 27 (3.9) & $153(7.4)$ & $252(8.7)$ & $70(6.9)$ \\
\hline Thyroid & $6(3.1)$ & $3(2.0)$ & $0(0.0)$ & $8(0.4)$ & $52(1.8)$ & $16(1.6)$ \\
\hline Lymphoma & $0(0.0)$ & $2(1.4)$ & $6(0.9)$ & $35(1.7)$ & $35(1.2)$ & $10(1.0)$ \\
\hline Plasmocytoma & $0(0.0)$ & $0(0.0)$ & $0(0.0)$ & $8(0.4)$ & $3(0.1)$ & $0(0.0)$ \\
\hline Melanoma & $0(0.0)$ & $0(0.0)$ & $0(0.0)$ & $66(3.2)$ & $49(1.7)$ & $1(0.1)$ \\
\hline Gastrointestinal & $1(0.6)$ & $2(1.4)$ & $10(1.4)$ & 27 (1.3) & $81(2.8)$ & $34(3.4)$ \\
\hline Liver & $0(0.0)$ & $0(0.0)$ & $0(0.0)$ & $6(0.3)$ & $38(1.3)$ & $45(4.5)$ \\
\hline Other & $18(9.3)$ & $8(5.4)$ & $44(6.5)$ & $143(6.9)$ & $438(15.1)$ & $161(15.9)$ \\
\hline \multicolumn{7}{|l|}{ Bone involvement } \\
\hline Femur & $138(72.2)$ & $85(58.4)$ & $566(83.2)$ & 1554 (75.2) & $1876(64.7)$ & $981(97.1)$ \\
\hline Humerus & $53(27.8)$ & $61(41.6)$ & $110(16.2)$ & $482(23.3)$ & $998(34.4)$ & $26(2.6)$ \\
\hline Tibia & $0(0.0)$ & $0(0.0)$ & $4(0.5)$ & $31(1.5)$ & $26(0.9)$ & $3(0.3)$ \\
\hline \multicolumn{7}{|l|}{ Fixation method $(n=5856)$} \\
\hline Endoprosthesis & $34(17.7)$ & $18(12.1)$ & $134(19.7)$ & $606(29.3)$ & $1032(35.6)$ & $243(24.1)$ \\
\hline Arthroplasty & $49(25.8)$ & 71 (48.3) & $31(4.6)$ & $273(13.2)$ & $261(9.0)$ & $99(9.8)$ \\
\hline Intramedullary nail & 30 (15.8) & $31(21.5)$ & $283(41.6)$ & $878(42.5)$ & $1221(42.1)$ & $550(54.5)$ \\
\hline Open reduction and internal fixation & $78(40.7)$ & $26(18.1)$ & $232(34.1)$ & $296(14.3)$ & $255(8.8)$ & $35(3.5)$ \\
\hline Allograft prosthetic composite & $0(0.0)$ & $0(0.0)$ & $0(0.0)$ & $14(0.7)$ & $9(0.3)$ & $0(0.0)$ \\
\hline Cementoplasty & $0(0.0)$ & $0(0.0)$ & $0(0.0)$ & $0(0.0)$ & $122(4.2)$ & $83(8.2)$ \\
\hline
\end{tabular}

\section{Survival trends}

One-year survival was reported in 67 studies, 2-year survival in 39 and 5 -year survival in 18 . The average overall 1-year survival rate was $41 \%$ (95\% CI 37\%-45\%) across all decades; the rate for the most recent period, 2010-2018, was 29\% (95\% CI 22\%-38\%) (Figure 2A). Meta-regression analysis showed no significant effect of midpoint study year on 1-year survival ( $p=0.8), 2$-year survival $(p=0.6)$ or 5 -year survival $(p=0.6)$ (Figure 3). Heterogeneity among studies was high for 1-year $\left(I^{2}=89 \%\right), 2$-year $\left(I^{2}=84 \%\right)$ and 5 -year $\left(I^{2}=64 \%\right)$ survival. Median survival was reported in 39 studies, and mean survival was reported in 59 studies; these trends are depicted in Figure 4. Owing to the inconsistency in follow-up duration and reporting methods, meta-regression of mean and median survival was not performed.

\section{Primary tumours}

One-, 2- or 5-year survival by primary tumour type was reported in 12 studies. There were insufficient data to perform meta-regression; however, we were able to perform subgroup analysis for 1-year survival in 10 studies including patients with breast, renal and lung cancer. This analysis showed mean 1-year survival rates of $53 \%$ (95\% CI $\left.36 \%-71 \%, I^{2}=66 \%\right)$ from 1996 to 2016 for breast cancer, $66 \%\left(95 \%\right.$ CI $50 \%-79 \%, I^{2}=85 \%$ ) from 1987 to 2001 for renal cancer, and $41 \%$ (95\% CI $\left.22 \%-60 \%, I^{2}=11 \%\right)$ from 1996 to 2001 for lung cancer (Figure 5).

\section{Primary tumour severity}

Meta-regression showed no effect of tumour severity score on overall 1 -year survival $(p=0.9)$. Meta-regression including both severity score and midpoint year of study also showed no effect on 1-year survival $(p=0.3$ and 0.5 , respectively). This indicates that there was no association between the primary tumour severity score of published studies and 1-year overall survival.

\section{Mode of fixation}

Endoprosthetic reconstruction including tumour prosthesis or arthroplasty was performed in 2493 cases (42.6\%), 
A

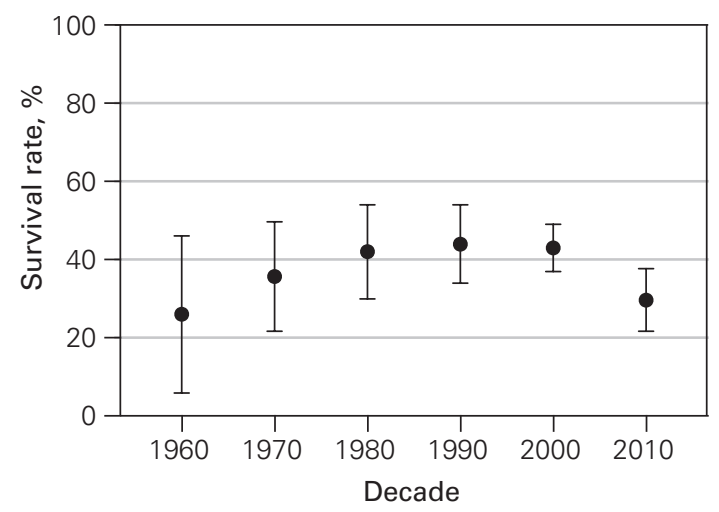

C

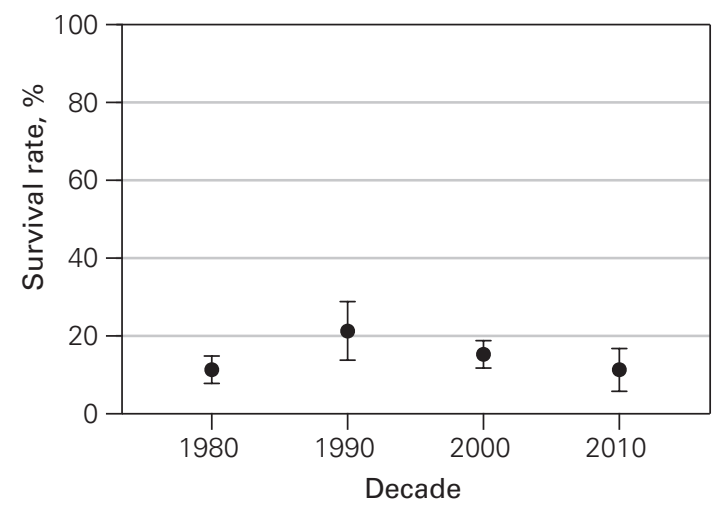

B

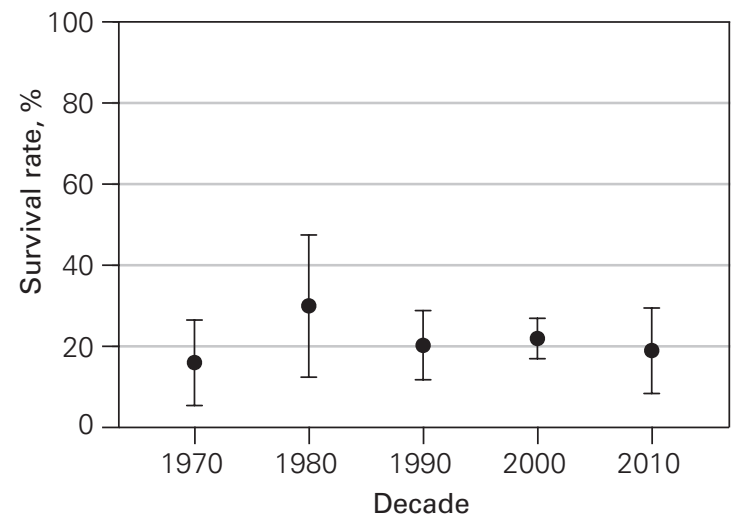

Fig. 2. Survival by decade of midpoint study year. A) 1-year, B) 2-year, and C) 5-year survival. Error bars represent standard deviations.

and intramedullary nailing or plating procedures were performed in 3184 cases (54.4\%) (Table 1). Mode of fixation by decade is presented in Figure 6 .

\section{Discussion}

The introduction of targeted molecular therapies and immune-based therapies as well as improved screening and diagnostic imaging has significantly improved survival outcomes for the general population of patients with metastatic cancer. ${ }^{11-15}$ Large population data sets have repeatedly shown improved outcomes for patients with metastatic breast, lung and renal cell cancer and melanoma. ${ }^{7-9}$ However, among the studies included in this review, 1-, 2and 5-year survival of patients with A-MBD undergoing orthopedic management did not improve statistically significantly from 1968 to 2018.

There are several possible explanations for the lack of observed improvement in our study. Bone metastases and skeletal-related events are known negative prognostic factors for overall survival. ${ }^{91-96}$ Furthermore, inferior clinical outcomes and lower therapeutic response rates have been reported in patients with bone metastases treated with novel immunotherapies and targeted molecular therapies compared to other sites of metastatic disease. ${ }^{97-100}$ Our results suggest that survival of patients with MBD who have undergone orthopedic surgery remains poor. With improved imaging techniques, metastatic disease is diagnosed much earlier than in previous decades. ${ }^{101}$ At the time patients require orthopedic intervention, the lead time of advanced imaging techniques may be negated, especially since the indications for orthopedic intervention have not changed over time, and hence this patient population actually has more advanced disease than generalized patients with metastatic cancer reported in large population data sets. $^{7-9}$ It is also possible that orthopedic intervention studies have yet to show the survival improvements trending in patients with advanced metastatic cancer. For example, Caswell-Jin and colleagues ${ }^{7}$ performed a systematic review to evaluate survival in patients with metastatic breast cancer and found no survival improvement from 1980 to 1990 but did find survival improvement from 1990 to 2010.

Another potential confounder is the higher proportion of primary cancers with the poorest prognosis (lung, liver, 
A

Midpoint
year

Koskinen et al. ${ }^{28}$
Critchley.
Katzner et al ${ }^{20}$
Dijstra et al. ${ }^{31}$
Lin et al..$^{21}$

Karachalios et al. ${ }^{32}$

Vandeweyer et al. ${ }^{33}$

Rompe et al. ${ }^{34}$

Rompe et al..$^{35}$

Wedin et al. ${ }^{36}$

Redmond et al. ${ }^{37}$

Katagiri et al. ${ }^{38}$

Hwang et al. ${ }^{39}$

Bickels et al. ${ }^{40}$

Kelly et al. ${ }^{41}$

Giannoudis et al. ${ }^{42}$

Ward et al. ${ }^{43}$

Nilsson et al. ${ }^{44}$

Hattori et al. ${ }^{45}$

Hattori et al 45

Camnasio et al. ${ }^{46}$ Weiss et al. ${ }^{47}$

Samsani et al. ${ }^{48}$

Sarahrudi et al. ${ }^{49}$

Sarahrudi et al. ${ }^{49}$ Selek et al. ${ }^{50}$

Scotti et al. ${ }^{51}$

Wedin et al. ${ }^{52}$

Casadei et al. ${ }^{53}$

Sarahrudi et al. ${ }^{54}$

Nakashima et al. ${ }^{55}$

Zacheri et al. ${ }^{56}$

Xing et al. ${ }^{57}$

Atesok et al. ${ }^{58}$

Henrichs et al. ${ }^{59}$

Faisham et al ${ }^{60}$

Weber et al. ${ }^{61}$

Wedin et al. ${ }^{62}$

Mavrogenis et al ${ }^{63}$

Chandrasekar et al. ${ }^{64}$

Hattori et al. ${ }^{45}$

Pretell et al. ${ }^{6}$

Muramatsu et al. ${ }^{66}$

Harvey et al. ${ }^{67}$

Laitinen et al. ${ }^{6}$

Moon et al. 69

Piccioli et al. ${ }^{70}$

Madhusudhan et al. ${ }^{7}$ Sezgin et al. ${ }^{72}$

Sørensen et al. ${ }^{73}$ Piccioli et al. ${ }^{74}$

Deschamps et al. ${ }^{75}$

Fakler et al. ${ }^{76} \quad 2008$

Choy et al. ${ }^{77} 2009$

Choi et al. ${ }^{78} \quad 2009$

Yu et al. ${ }^{79} 2010$

Yu et al. ${ }^{79} 2010$

Gao et al. ${ }^{80} 2011$

Gao et al. ${ }^{80} 2011$

Dim et al. ${ }^{81} 2011$

Huang et al. ${ }^{82} 2013$

Peterson et al. ${ }^{83} 2014$

Feng et al. ${ }^{84} 2016$

Park et al. ${ }^{85}$

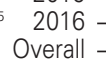
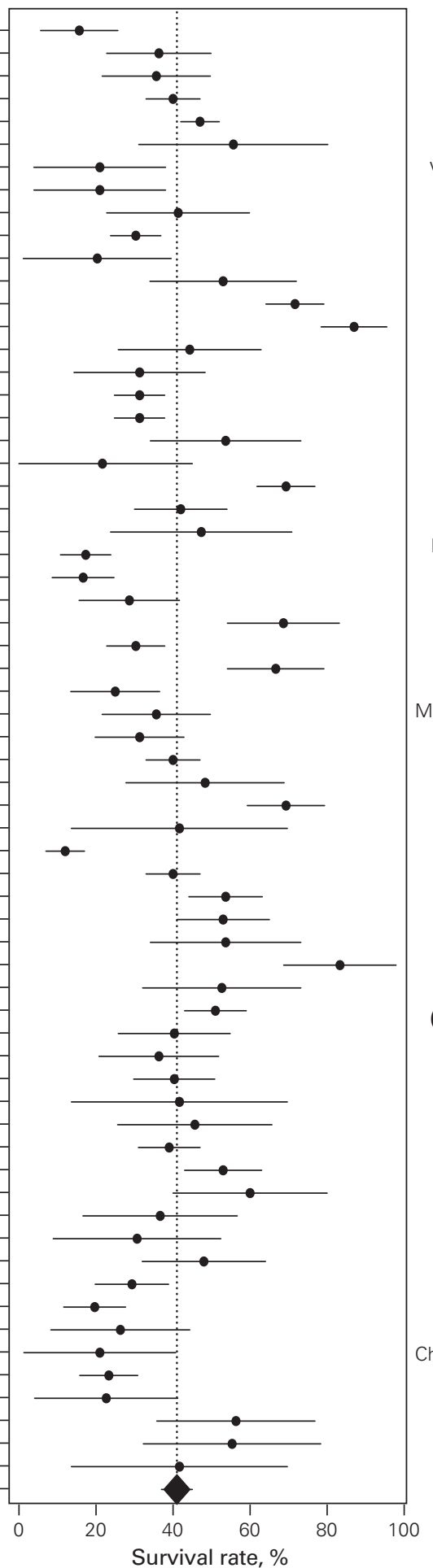

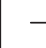

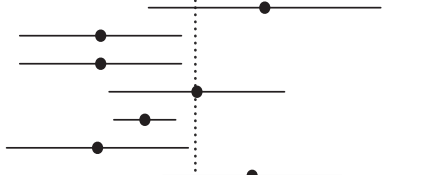

$-1$
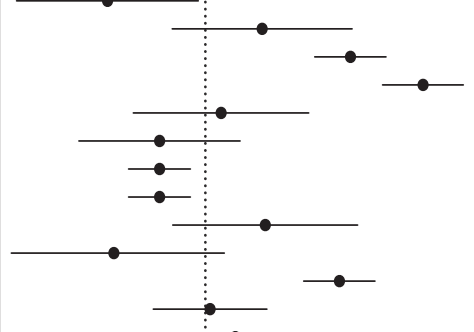

-1

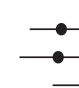

B

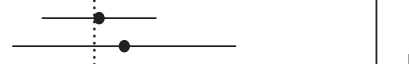

Atesok et al. ${ }^{58}$

Mavrogenis et al ${ }^{63} 2003$

Wedin et al. ${ }^{52} 2003$

Pretell et al. ${ }^{65} 2004$

Harvey et al. ${ }^{67} 2004$

Hattori et al. ${ }^{45} 2004$

Muramatsu et al. ${ }^{66} 2004$

Moon et al. ${ }^{69} 2005$

Madhusudhan et al. ${ }^{71} 2005$

Piccioli et al. ${ }^{70} 2005$

Sørensen et al. ${ }^{73} 2006$

Tanaka et al. ${ }^{87} 2008$

Choy et al. ${ }^{77} 2009$

Yu et al. ${ }^{79} 2010$

Yu et al. ${ }^{79} 2010$

Hovgaard et al. ${ }^{88} 2011$

Huang et al. ${ }^{82} 2013$

Feng et al. $^{84} 2016$

Overall

C

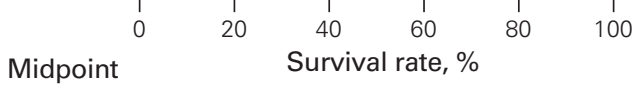

year

Lin et al. ${ }^{21} 1989$

Huang et al. ${ }^{82} 1994$

Kelly et al. ${ }^{41} 1996$

Potter et al. ${ }^{89} 1998$

Camnasio et al. ${ }^{46} 1998$

Scotti et al. ${ }^{51} 1999$

Weiss et al. ${ }^{47} 1999$

Casadei et al.53 2000

Henrichs et al. ${ }^{59} 2001$

Atesok et al. ${ }^{58} 2001$

Mavrogenis et al. ${ }^{63} 2003$

Muramatsu et al.66 2004

Chandrasekar et al. ${ }^{64} 2004$

Harvey et al. ${ }^{67} 2004$

Pretell et al. ${ }^{65} 2004$

Sezgin et al. ${ }^{72} 2006$

Calabro et al 902007

Hovgaard et al. ${ }^{88}$

2011
Overall

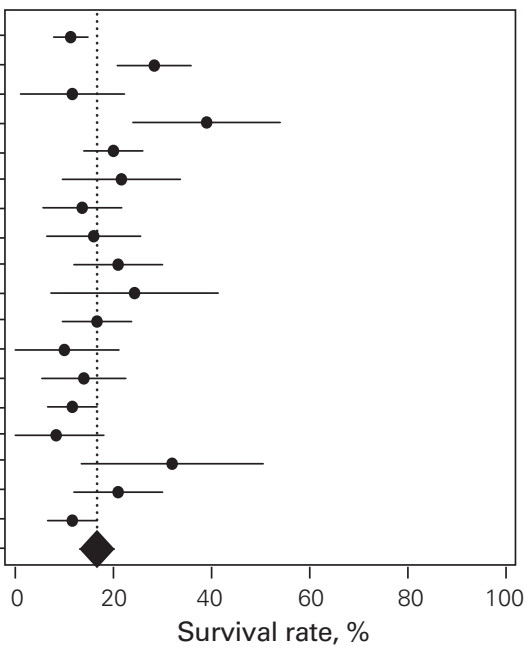

Fig. 3. Estimates of A) 1-year, B) 2-year, and C) 5-year survival by midpoint year of patient inclusion. Error bars represent standard deviations. 


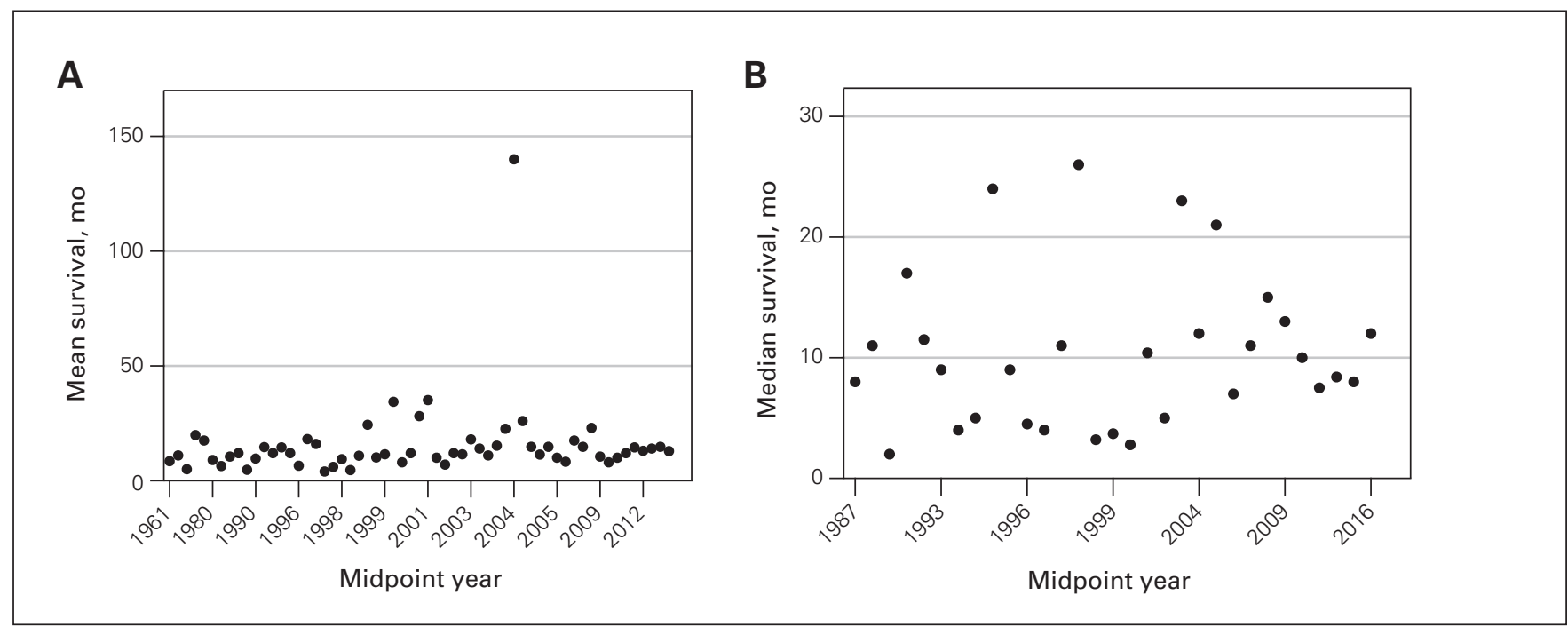

Fig. 4. A) mean survival by midpoint year of patient inclusion. B) median survival by midpoint year of patient inclusion.

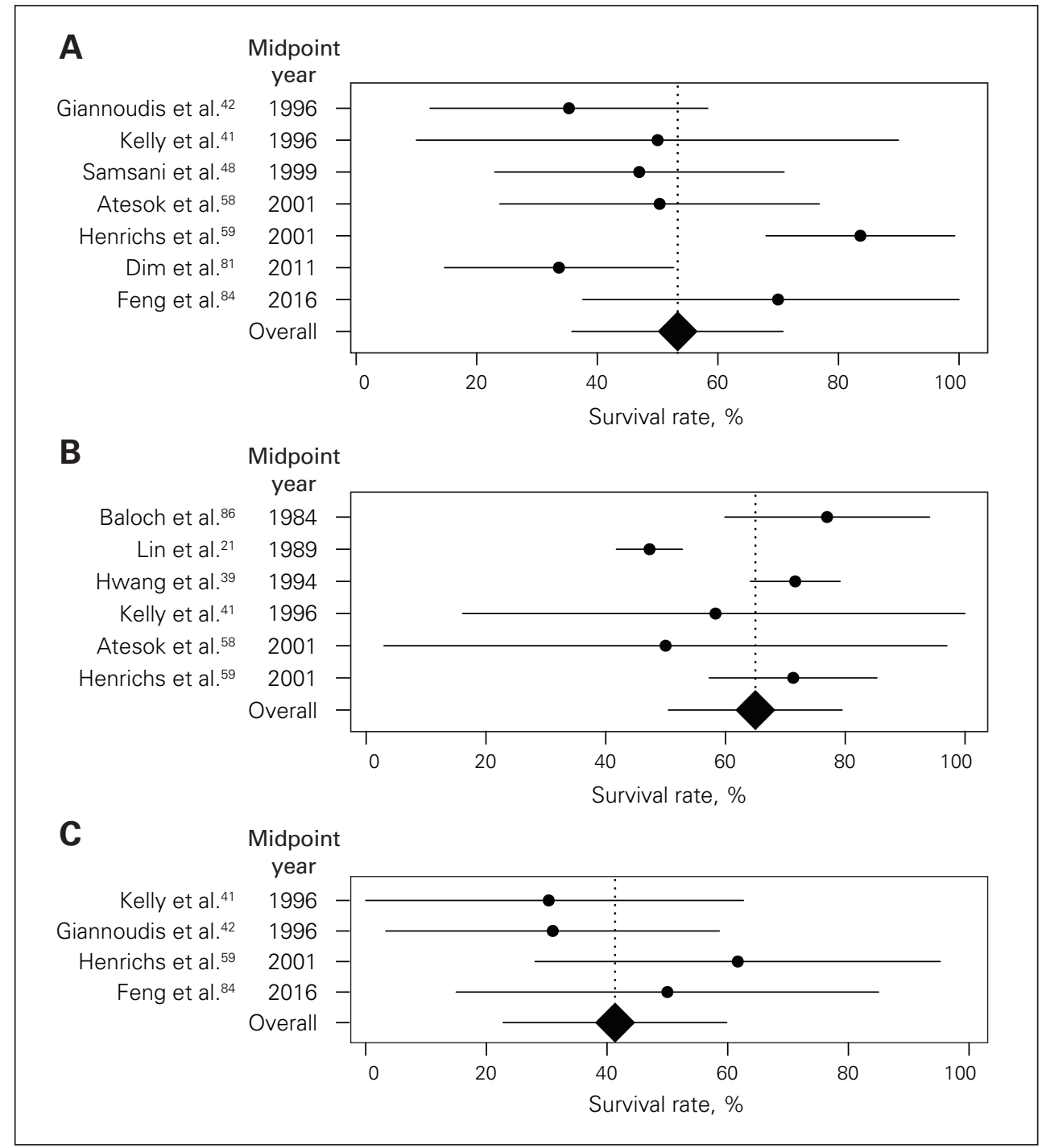

Fig. 5. Subgroup analysis of 1-year survival for A) breast cancer, B) renal cell cancer, and C) lung cancer by midpoint year of patient inclusion. Error bars represent standard deviations. 


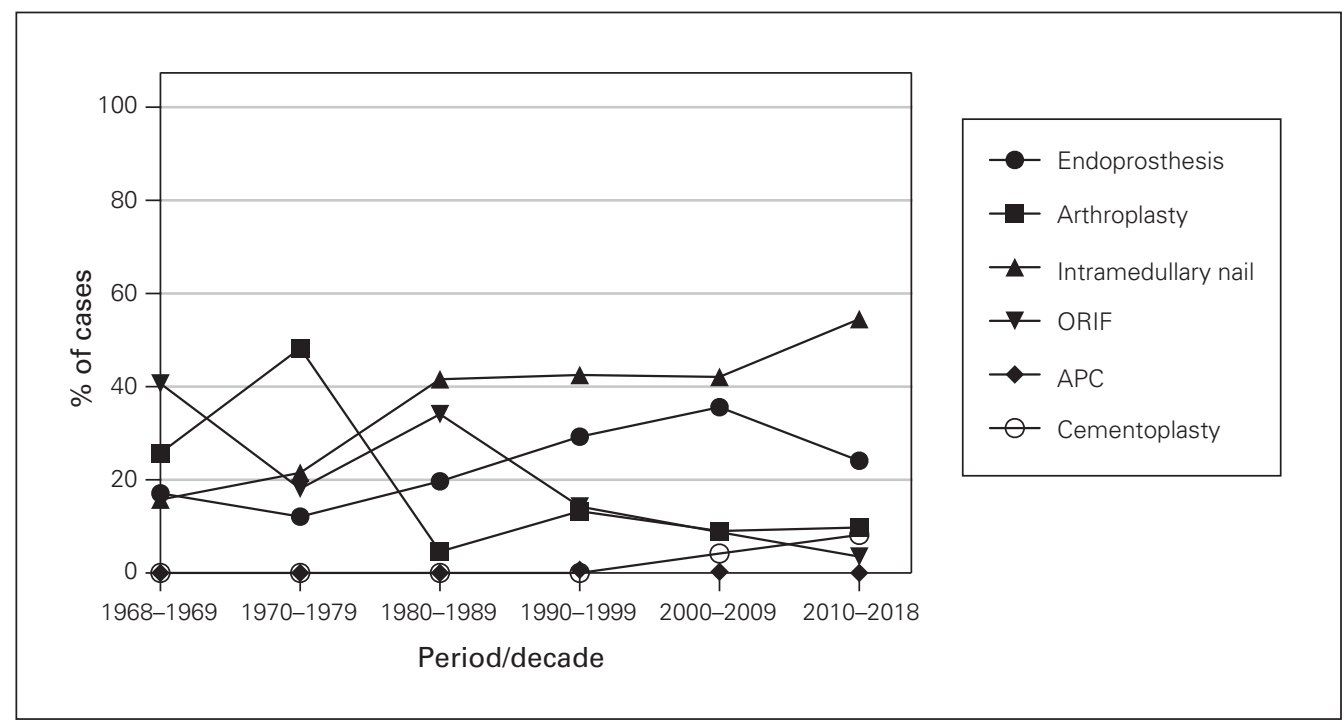

Fig. 6. Fixation method by period/decade. $A P C=$ allograft prosthetic composite; ORIF = open reduction and internal fixation.

gastrointestinal, renal) represented in more recent publications. To address this, we performed a meta-regression examining tumour severity score, as defined by recent SEER data on 5 -year prognosis by primary tumour type, ${ }^{5}$ which did not show a significant effect on 1-year survival. Meta-regression including both severity score and midpoint year of study also showed no effect on 1-year survival. This supports the hypothesis that patients with A-MBD requiring orthopedic surgery represent a population with a very poor prognosis, regardless of primary tumour type. However, these results were likely influenced by the substantial heterogeneity between studies, and our analysis may not adequately model the effect of primary tumour type on survival after orthopedic surgery.

We were unable to analyze other important prognostic factors, such as the presence of visceral metastasis, multiple bony lesions, Eastern Cooperative Oncology Group Scale of Performance Status and pathologic fracture, that help surgeons predict survival in this population. . $^{3,21,102-104}$ Predictive clinical decision-support tools such as PATHFx (https://www.pathfx.org) that account for these variables may be used to provide objective data on life expectancy to surgeons and patients, and assist surgical decision-making. ${ }^{104}$

We performed subgroup analysis only for breast, renal and lung cancer, as there were insufficient data to perform subgroup analysis for all tumour types. Breast cancer is commonly reported as a positive predictor of survival, with 1 -year survival rates in the literature ranging from $45 \%$ to $59 \%{ }^{2,24}$ The mean 1-year survival rate in our study was $53 \%$ (95\% CI 36\%-71\%). Variable survival rates have been reported for renal cell carcinoma..$^{24,102,103,105} \mathrm{We}$ found a mean 1-year survival rate of $66 \%$ (95\% CI 50\%-79\%). Lung cancer is commonly a negative prognostic indicator, with a reported 1 -year survival rate of $30 \% .^{18,24,106}$ The mean 1-year survival rate in our study was $41 \%$ (95\% CI $22 \%-60 \%)$. Consistent with previous studies, ${ }^{3,105}$ the femur was the most common location of metastatic disease. There were insufficient data on outcomes by location of bone lesion to perform subgroup analysis.

\section{Limitations}

The low MINORS scores of the included studies is perhaps the largest limitation of our study. The majority of the included studies were of level IV evidence. This is consistent with previous systematic reviews on this topic, which also identified largely level IV evidence and substantial heterogeneity in study methodology. ${ }^{3,17}$ As a result, we expected that heterogeneity would be present in our review owing to the large range of years included, variable intervention types, broad patient demographic characteristics and retrospective nature of the literature in this area. Despite this heterogeneity, we feel that meta-regression was justified for analyzing the survival trends over time given the number of studies reporting 1-, 2- and 5-year survival. Owing to small numbers, we were not able to evaluate survival in specific subsets of patients with a more favourable prognosis, such as those with solitary or oligometastatic disease.

Other limitations include lack of reporting of information on primary tumour type, fixation method and survival specific to primary tumour. We were able to perform subgroup analysis of 1-year survival only for breast, renal and lung cancer owing to small numbers.

Adjuvant treatments, including radiotherapy, chemotherapy and newer immunotherapies, can influence survival. These were poorly reported in the included studies and were therefore not extracted. Varying definitions of outcome, including the type of survival statistic reported, 
as well as varying duration of follow-up limited analysis substantially. We were unable to analyze mean and median survival with meta-regression owing to the heterogeneity in reporting, which limited the number of studies that could be included in the meta-regression model. In addition, the majority of patients who underwent orthopedic surgery for A-MBD between 1968 and 2018 would not be reported on in the published series, which introduced a publication bias.

Many of these identified limitations could be best addressed with a Canadian prospective registry, such as the Scandinavian Sarcoma Group registry. ${ }^{105}$

\section{Conclusion}

We found no improvement in overall survival between 1968 and 2018 for patients with surgically treated A-MBD. This finding is discordant with recent findings of improvements in survival over time in the general population of patients with metastatic cancer. The survival improvements observed in large population-based data sets may not reflect the poor outcomes associated with the subset of patients with A-MBD requiring orthopedic surgery. There remains a critical need to improve prospective data collection in this population to facilitate personalized surgical decision-making for this complex and diverse patient population.

Acknowledgement: The authors thank the Alberta Strategy for Patient-Oriented Research (SPOR) SUPPORT Unit for support with this work.

Affiliations: From the Section of Orthopaedic Surgery, Department of Surgery, University of Calgary, Calgary, Alta. (Abbott, Kendal, Hewison, Puloski, Monument); the McCaig Institute for Bone and Joint Health, University of Calgary, Calgary, Alta. (Puloski, Monument); and the Arnie Charbonneau Cancer Institute, University of Calgary, Calgary, Alta. (Monument).

Competing interests: None declared.

Contributors: A. Abbott, J. Kendal, S. Puloski and M. Monument designed the study. A. Abbott, J. Kendal, C. Hewison and M. Monument acquired the data, which all authors analyzed. A. Abbott, J. Kendal and M. Monument wrote the manuscript, which all authors critically revised. All authors gave final approval of the article to be published.

Content licence: This is an Open Access article distributed in accordance with the terms of the Creative Commons Attribution (CC BYNC-ND 4.0) licence, which permits use, distribution and reproduction in any medium, provided that the original publication is properly cited, the use is noncommercial (i.e., research or educational use), and no modifications or adaptations are made. See: https://creativecommons. org/licenses/by-nc-nd/4.0/.

\section{References}

1.Li S, Peng Y, Weinhandl ED, et al. Estimated number of prevalent cases of metastatic bone disease in the US adult population. Clin Epidemiol 2012;4:87-93.

2.Johnson CN, Gurich RW, Pavey GJ, et al. Contemporary management of appendicular skeletal metastasis by primary tumor type. 7 Am Acad Orthop Surg 2019;27:345-55.
3. Wood TJ, Antonelle R, Yeung H, et al. Surgical management of bone metastases: quality of evidence and systematic review. Ann Surg Oncol 2014;21:4081-9.

4. Errani C, Mavrogenis AF, Cevolani L, et al. Treatment for long bone metastases based on a systematic literature review. Eur 7 Orthop Surg Traumatol 2017;27:205-11.

5.SEER Cancer Statistics Review (CSR) 1975-2016; updated 2020 Apr. 9. Relative survival rates by year of diagnosis, April 2018. Bethesda (MD): Surveillance, Epidemiology, and End Results Program, National Cancer Institute.

6. Jemal A, Ward EM, Johnson CJ, et al. Annual report to the nation on the status of cancer, 1975-2014, featuring survival. 7 Natl Cancer Inst 2017;109: djx030.

7. Caswell-Jin JL, Plevritis SK, Tian L, et al. Changes in survival in metastatic breast cancer with treatment advances: meta-analysis and systematic review. 7NCI Cancer Spectr 2018;2:1-10.

8. Rao A, Wiggins C, Lauer RC. Survival outcomes for advanced kidney cancer patients in the era of targeted therapies. Ann Transl Med 2018;6:165.

9. Lu T, Yang X, Huang Y, et al. Trends in the incidence, treatment and survival of patients with lung cancer in the last four decades. Cancer Manag Res 2019;11:943-53.

10. Dawood S, Broglio K, Gonzalez-Angulo AM, et al. Trends in survival over the past two decades among white and black patients with newly diagnosed stage IV breast cancer. 7 Clin Oncol 2008;26: 4891-8.

11. Rusch VW, Chaft J, Hellmann M. KEYNOTE-024: Unlocking a pathway to lung cancer cure? $\mathcal{F}$ Thorac Cardiovasc Surg 2018;155: 1777-80.

12. Hellmann MD, Ciuleanu TE, Pluzanski A, et al. Nivolumab plus ipilimumab in lung cancer with a high tumor mutational burden. $N$ Engl 7 Med 2018;378:2093-104.

13. Swain SM, Baselga J, Kim SB, et al. Pertuzumab, trastuzumab, and docetaxel in HER2-positive metastatic breast cancer. $N$ Engl 7 Med 2015;372:724-34.

14.Choueiri TK, Hessel C, Halabi S, et al. Cabozantinib versus sunitinib as initial therapy for metastatic renal cell carcinoma of intermediate or poor risk (Alliance A031203 CABOSUN randomised trial): progression-free survival by independent review and overall survival update. Eur 7 Cancer 2018;94:115-25.

15. Wolchok JD, Chiarion-Sileni V, Gonzalez R, et al. Overall survival with combined nivolumab and ipilimumab in advanced melanoma. $N$ Engl 7 Med 2017;377:1345-56.

16. Swanson KC, Pritchard DJ, Sim FH. Surgical treatment of metastatic disease of the femur. 7 Am Acad Orthop Surg 2000;8:56-65.

17.Janssen SJ, Teunis T, Hornicek FJ, et al. Outcome after fixation of metastatic proximal femoral fractures: a systematic review of 40 studies. 7 Surg Oncol 2016;114:507-19.

18. Nathan SS, Healey JH, Mellano D, et al. Survival in patients operated on for pathologic fracture: implications for end-of-life orthopedic care. 7 Clin Oncol 2005;23:6072-82.

19. Coleman RE, Lipton A, Roodman GD, et al. Metastasis and bone loss: advancing treatment and prevention. Cancer Treat Rev 2010;36: 615-20.

20. Forsberg JA, Wedin R, Bauer H. Which implant is best after failed treatment for pathologic femur fractures? Clin Orthop Relat Res 2013; 471:735-40.

21. Lin PP, Mirza AN, Lewis VO, et al. Patient survival after surgery for osseous metastases from renal cell carcinoma. 7 Bone foint Surg Am 2007;89:1794-801.

22. Krygier JE, Lewis VO, Cannon CP, et al. Operative management of metastatic melanoma in bone may require en bloc resection of disease. Clin Orthop Relat Res 2014;472:3196-203.

23. Briasoulis E, Karavasilis V, Kostadima L, et al. Metastatic breast carcinoma confined to bone: portrait of a clinical entity. Cancer 2004; 101:1524-8. 
24. Kirkinis MN, Lyne CJ, Wilson MD, et al. Metastatic bone disease: a review of survival, prognostic factors and outcomes following surgical treatment of the appendicular skeleton. Eur 7 Surg Oncol 2016;42: 1787-97.

25. Kendal JK, Abbott A, Kooner S, et al. A scoping review on the surgical management of metastatic bone disease of the extremities. BMC Musculoskelet Disord 2018;19:279.

26. Slim K, Nini E, Forestier D, et al. Methodological Index for NonRandomized Studies (MINORS): development and validation of a new instrument. ANZ 7 Surg 2003;73:712-6.

27. Spindler KP, Kuhn JE, Dunn W, et al. Reading and reviewing the orthopaedic literature: a systematic, evidence-based medicine approach. 7 Am Acad Orthop Surg 2005;13:220-9.

28. Koskinen EV, Nieminen RA. Surgical treatment of metastatic pathological fractures of major long bones. Acta Orthop Scand 1973;44:539-49.

29. Critchley M. Surgery for long bone metastases. ANZ 7 Surg 1971;40: 279-84.

30. Katzner M, Jacquemarie B, Schvingt E. Surgical treatment of malignant secondary tumors of the humerus: report of 45 cases. Arch Orthop Trauma Surg 1979;94:293-8.

31.Dijstra S, Wiggers T, van Geel BN, et al. Impending and actual pathological fractures in patients with bone metastases of the long bones. A retrospective study of 233 surgically treated fractures. Eur 7 Surg 1994;160:535-42.

32. Karachalios T, Atikins RM, Sarangi PP, et al. Reconstruction nailing for pathological subtrochanteric fractures with coexisting femoral shaft metastases. F Bone foint Surg Br 1993;75:119-22.

33. Vandeweyer E, Gebhart M. Treatment of humeral pathological fractures by internal fixation and methylmetacrylate injection. Eur 7 Surg Oncol 1997;23:238-42.

34. Rompe J, Eysel P, Hopf C, et al. Metastatic instability at the proximal end of the femur: comparison of endoprosthetic replacement and plate osteosynthesis. Arch Orthop Trauma Surg 1994;113:260-4.

35. Rompe J, Eysel P, Hopf C, et al. Use of the tumor prosthesis in secondary neoplastic destruction of the proximal end of the femur [article in German]. Z Orthop Ibre Grenzgeb 1993;131:446-51.

36. Wedin R, Hansen B, Laitinen M, et al. Complications and survival after surgical treatment of 214 metastatic lesions of the humerus. 7 Shoulder Elbow Surg 2012;21:1049-55.

37. Redmond BJ, Biermann JS, Blasier RB. Interlocking intramedullary nailing of pathological fractures of the shaft of the humerus. 7 Bone foint Surg Am 1996;78:891-6.

38. Katagiri H, Sato K, Takahashi M, et al. Use of adriamycinimpregnated methylmethacrylate in the treatment of tumor metastases in the long bones. Arch Orthop Trauma Surg 1997;116:329-33.

39. Hwang N, Nandra R, Grimer R, et al. Massive endoprosthetic replacement for bone metastases resulting from renal cell carcinoma: factors influencing patient survival. Eur F Surg Oncol 2014;40:429-34.

40. Bickels J, Kollender Y, Wittig J, et al. Function after resection of humeral metastases: analysis of 59 consecutive patients. Clin Orthop Relat Res 2005;(437):201-8.

41. Kelly C, Wilkins R, Eckardt J, et al. Treatment of metastatic disease of the tibia. Clin Orthop Relat Res 2003;(415 Suppl):S219-29.

42. Giannoudis PV, Bastawrous SS, Bunola JA, et al. Unreamed intramedullary nailing for pathological femoral fractures: good results in 30 cases. Acta Orthop Scand 1999;70:29-32.

43. Ward WG, Holsenbeck S, Dorey F, et al. Metastatic disease of the femur: surgical treatment. Clin Orthop Relat Res 2003;(415 Suppl): S230-44.

44. Nilsson J, Gustafson P. Surgery for metastatic lesions of the femur: good outcome after 245 operations in 216 patients. Injury 2008:39:404-10.

45. Hattori H, Mibe J, Yamamamoto K. Modular megaprosthesis in metastatic bone disease of the femur. Orthopedics 2011;34:e871-6.

46. Camnasio F, Scotti C, Peretti G, et al. Prosthetic joint replacement for long bone metastases: analysis of 154 cases. Arch Orthop Trauma Surg 2008;128:787-93.
47.Weiss KR, Bhumbra R, Biau DJ, et al. Fixation of pathological humeral fractures by the cemented plate technique. 7 Bone foint Surg Br 2011;93:1093-7.

48. Samsani SR, Panikkar V, Georgiannos D, et al. Subtrochanteric metastatic lesions treated with the long gamma nail. Int Orthop 2003;27: 298-302.

49. Sarahrudi K, Wolf H, Funovics P, et al. Surgical treatment of pathological fractures of the shaft of the humerus. F Trauma 2009;66:789-94.

50. Selek H, Basarir K, Yildiz Y, et al. Cemented endoprosthetic replacement for metastatic bone disease in the proximal femur. 7 Arthroplasty 2008;23:112-7.

51. Scotti C, Camnasio F, Peretti G, et al. Modular prostheses in the treatment of proximal humerus metastases: review of 40 cases. $\mathcal{F}$ Orthop Traumatol 2008;9:5-10.

52. Wedin R, Bauer HC, Wersall P. Failure after operation for skeletal metastatic lesions of long bones. Clin Orthop Relat Res 1999;(358): 128-39.

53. Casadei R, De Paolis M, Drago G, et al. Total elbow arthroplasty for primary and metastatic tumor. Orthop Traumatol Surg Res 2016;102: $459-65$.

54. Sarahrudi K, Greitbauer M, Platzer P, et al. Surgical treatment of metastatic fractures of the femur: a retrospective analysis of 142 patients. 7 Trauma 2009;66:1158-63.

55. Nakashima H, Katagiri H, Takahashi M, et al. Survival and ambulatory function after endoprosthetic replacement for metastatic bone tumor of the proximal femur. Nagoya 7 Med Sci 2010;72:13-21.

56.Zacheri M, Gruber S, Glehr M, et al. Surgery for pathological proximal femoral fractures, excluding femoral head and neck fractures: resection vs. stabilization. Int Orthop 2011;35:1537-43.

57. Xing Z, Moon BS, Satcher RL, et al. A long femoral stem is not always required in hip arthroplasty for patients with proximal femur metastases tumor. Clin Orthop Relat Res 2013;471:1622-7.

58. Atesok K, Liebergall M, Sucher E, et al. Treatment of pathological humeral shaft fractures with unreamed humeral nail. Ann Surg Oncol 2007;14:1493-8.

59. Henrichs M, Krebs J, Gosheger G, et al. Modular tumor endoprostheses in surgical palliation of long-bone metastases: a reduction in tumor burden and a durable reconstruction. World 7 Surg Oncol 2014; 12:330.

60. Faisham W, Zulmi W, Biswal B. Metastatic disease of the proximal femur. Med 7 Malaysia 2003;58:120-4.

61. Weber KL, Randal RL, Grossman S, et al. Management of lowerextremity bone metastases. 7 Bone Foint Surg Am 2006;88A:11-9.

62. Wedin R, Bauer HCF. Surgical treatment of skeletal metastatic lesions of the proximal femur: Endoprosthesis or reconstruction nail? 7 Bone foint Surg Br 2005;87:1653-7.

63. Mavrogenis AF, Pala E, Romagnoli C, et al. Survival analysis of patients with femoral metastases. F Surg Oncol 2012;105:135-41.

64. Chandrasekar CR, Grimer RJ, Carter SR, et al. Modular endoprosthetic replacement for tumours of the proximal femur. 7 Bone foint Surg Br 2009;91:108-12.

65.Pretell J, Rodriguez J, Blanco D, et al. Treatment of pathological humeral shaft fractures with intramedullary nailing. A retrospective study. Int Orthop 2010;34:559-63.

66. Muramatsu K, Ihara K, Iwanagaa R, et al. Treatment of metastatic bone lesions in the upper extremity: indications for surgery. Orthopedics 2010;33:807.

67. Harvey N, Ahlmann ER, Allison DC, et al. Endoprostheses last longer than intramedullary devices in proximal femur metastases. Clin Orthop Relat Res 2012;470:684-91.

68. Laitinen M, Nieminen J, Pakarinen T. Treatment of pathological humerus shaft fractures with intramedullary nails with or without cement. Arch Orthop Trauma Surg 2011;13:503-8.

69. Moon B, Lin P, Satcher R, et al. Intramedullary nailing of femoral diaphyseal metastases: Is it necessary to protect the femoral neck? Clin Orthop Relat Res 2015;473:1499-1502. 
70. Piccioli A, Rossi B, Scaramuzzo L, et al. Intramedullary nailing for treatment of pathologic femoral fractures due to metastases. Injury 2014:45:412-7.

71. Madhusudhan TR, Shetty SK, Ramesh B, et al. Cannulated interlocking titanium prosthesis in pathological proximal femoral fractures: a prospective study. Eur 7 Orthop Surg Traumatol 2009;19:315-9.

72. Sezgin H, Çıraklı A, Göçer H, et al. Reconstruction of lower extremity primary malignant and metastatic bone tumours with modular endoprosthesis. Niger 7 Clin Pract 2017;20:1127-32.

73. Sørensen MS, Gregersen KG, Grum-Schwensen T, et al. Patient and implant survival following joint replacement because of metastatic bone disease. Acta Orthop 2013;84:301-6.

74. Piccioli A, Maccauro G, Scaramuzzo L, et al. Surgical treatment of impending and pathological fractures of tibia. Injury 2013;44:1092-6.

75. Deschamps F, Farouil G, Hakime A, et al. Cementoplasty of metastases of the proximal femur: Is it a safe palliative option? $\mathcal{F}$ Vasc Interv Radiol 2012;23:1311-6.

76. Fakler J, Hase F, Bohme J, et al. Safety aspects in surgical treatment of pathological fractures of the proximal femur: modular endoprosthetic replacement versus intramedullary nailing. Patient Saf Surg 2013;7:37.

77. Choy WS, Kim KJ, Lee SK, et al. Surgical treatment of pathological fractures occurring at the proximal femur. Yonsei Med 7 2015;56:460-5.

78. Choi ES, Han I, Cho HS, et al. Intramedullary nailing for pathological fractures of the proximal humerus. Clin Orthop Surg 2016; $8: 458-64$

79. Yu Z, Xiong Y, Shi R, et al. Surgical management of metastatic lesions of the proximal femur with pathological fractures using intramedullary nailing or endoprosthetic replacement. Mol Clin Oncol 2018;8:107-14

80. Gao H, Liu Z, Wang B, et al. Clinical and functional comparison of endoprosthetic replacement with intramedullary nailing for treating proximal femur metastasis. Chin 7 Cancer Res 2016;28:209-14.

81.Dim EM, Yau CHR, Ho WYK, et al. Profile of surgically-treated metastatic extremity bone tumours at a university hospital in Hong Kong. 7 Orthop Trauma Rehabil 2018;24:1-8.

82. Huang L, Guo W, Yang R, et al. Surgical managements for bone metastases in tibia of 16 cases [article in Chinese]. Beijing Da Xue Xue Bao Yi Xue Ban 2013;45:752-6.

83. Peterson JR, Decilveo AP, O'Connor IT, et al. What are the functional results and complications with long stem hemiarthroplasty in patients with metastases to the proximal femur? Clin Orthop Relat Res 2017;475:745-56.

84. Feng H, Wang J, Guo P, et al. CT-guided percutaneous femoroplasty (PFP) for the treatment of proximal femoral metastases. Pain Physician 2016;19:e767-73.

85. Park JW, Kim YI, Kang HG, et al. Preliminary results: use of multihole injection nails for intramedullary nailing with simultaneous bone cement injection in long-bone metastasis. Skeletal Radiol 2019; 48:219-25.

86. Baloch KG, Grimer RJ, Carter SR, et al. Radical surgery for the solitary bony metastasis from renal-cell carcinoma. Eur 7 Surg Oncol 2014;40:429-34.

87. Tanaka T, Imanishi J, Charoenlap C, et al. Intramedullary nailing has sufficient durability for metastatic femoral fractures. World 7 Surg Oncol 2016; 14:80.

88. Hovgaard TB, Horstmann PF, Petersen MM, et al. Patient survival following joint replacement due to metastatic bone disease: comparison of overall patient and prostheses survival between cohorts treated in two different time-periods. Acta Oncol 2018;57:839-48.
89. Potter B, Chow V, Adams S, et al. Endoprosthetic proximal femur replacement: metastatic versus primary tumors. Surg Oncol 2009;18: 343-9.

90. Calabro T, Van Rooyen R, Piraino I, et al. Reconstruction of the proximal femur with a modular resection prosthesis. Eur 7 Orthop Surg Traumatol 2016;26:415-421.

91.Langer C, Hirsh V. Skeletal morbidity in lung cancer patients with bone metastases: demonstrating the need for early diagnosis and treatment with bisphosphonates. Lung Cancer 2010;67:4-11.

92. Negrier S, Escudier B, Gomez F, et al. Prognostic factors of survival and rapid progression in 782 patients with metastatic renal carcinomas treated by cytokines: a report from the Groupe français d'immunotherapie. Ann Oncol 2002;13:1460-8.

93. Fujimoto D, Ueda H, Shimizu R, et al. Features and prognostic impact of distant metastasis in patients with stage IV lung adenocarcinoma harboring EGFR mutations: importance of bone metastasis. Clin Exp Metastasis 2014;31:543-51.

94. Hsu F, Caluewe AD, Anderson D, et al. Patterns of spread and prognostic implications of lung cancer metastasis in an era of driver mutations. Curr Oncol 2017;24:228-33.

95. Barth A, Wanek LA, Morton DL. Prognostic factors in 1,521 melanoma patients with distant metastases. F Am Coll Surg 1995;181:193201.

96. Ruatta F, Derosa L, Escudier B, et al. Prognosis of renal cell carcinoma with bone metastases. Experience from a large cancer centre. Eur 7 Cancer 2019;107:79-85.

97. Landi L, D'Incà F, Gelibter A, et al. Bone metastases and immunotherapy in patients with advanced non-small-cell lung cancer. $f$ Immunother Cancer 2019;7:316-25.

98. Schmid S, Diem S, Li Q, et al. Organ-specific response to nivolumab in patients with non-small cell lung cancer. Cancer Immunol Immunother 2018;67:1825-32.

99. McKay RR, Kroeger N, Xie W, et al. Impact of bone and liver metastases on patients with renal cell carcinoma treated with targeted therapy. Eur Urol 2014;65:577-84.

100. Bueselinck B, Oudard S, Rixe O, et al. Negative impact of bone metastasis on outcome in clear-cell renal cell carcinoma treated with sunitinib. Ann Oncol 2011;22:794-800.

101. Tevaarwerk AJ, Gray RJ, Schneider BP, et al. Survival in metastatic recurrent breast cancer after adjuvant chemotherapy: little evidence for improvement over the past three decades. Cancer 2013; 119:1140-8

102. Katagiri H, Okada R, Takagi T, et al. New prognostic factors and scoring system for patients with skeletal metastasis. Cancer Med 2014; 3:1359-67

103. Bauer HC, Wedin R. Survival after surgery for spinal and extremity metastases. Prognostication in 241 patients. Acta Orthop Scand 1995; 66:143-6.

104.Forsberg JA, Wedin R, Boland PJ, et al. Can we estimate shortand intermediate-term survival in patients undergoing surgery for metastatic bone disease? Clin Orthop Relat Res 2017;475: 1252-61.

105. Ratasvuori M, Wedin R, Keller J, et al. Insight opinion to surgically treated metastatic bone disease: Scandinavian Sarcoma Group Skeletal Metastasis Registry report of 1195 operated skeletal metastasis. Surg Oncol 2013;22:132-8.

106. Suguira H, Yamada K, Suguira T, et al. Predictors of survival in patients with bone metastasis of lung cancer. Clin Orthop Relat Res 2008;466:729-36. 